\title{
Elbow Positioning and Joint Insufflation Substantially Influence Median and Radial Nerve Locations
}

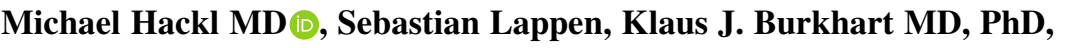 \\ Tim Leschinger MD, Martin Scaal PhD, Lars P. Müller MD, PhD, \\ Kilian Wegmann MD
}

Received: 3 April 2015/Accepted: 29 June 2015 / Published online: 8 July 2015

(C) The Association of Bone and Joint Surgeons (B) 2015

\begin{abstract}
Background The median and radial nerves are at risk of iatrogenic injury when performing arthroscopic arthrolysis with anterior capsulectomy. Although prior anatomic studies have identified the position of these nerves, little is known about how elbow positioning and joint insufflation might influence nerve locations.

Questions/purposes In a cadaver model, we sought to determine whether (1) the locations of the median and

Each author certifies that he or she, or a member of his or her immediate family, has no funding or commercial associations (eg, consultancies, stock ownership, equity interest, patent/licensing arrangements, etc) that might pose a conflict of interest in connection with the submitted article.

All ICMJE Conflict of Interest Forms for authors and Clinical Orthopaedics and Related Research ${ }^{\mathbb{R}}$ editors and board members are on file with the publication and can be viewed on request.

Clinical Orthopaedics and Related Research ${ }^{\mathbb{R}}$ neither advocates nor endorses the use of any treatment, drug, or device. Readers are encouraged to always seek additional information, including FDA approval status, of any drug or device before clinical use. Each author certifies that his or her institution approved the human protocol for this investigation, that all investigations were conducted in conformity with ethical principles of research, and that informed consent for participation in the study was obtained.

This work was performed at the Department of Anatomy, University of Cologne, Cologne, Germany.
\end{abstract}

M. Hackl ( $ه)$, S. Lappen, T. Leschinger, L. P. Müller, K. Wegmann

Center for Orthopedic and Trauma Surgery, University Medical

Center of Cologne, Kerpener Strasse 62, 50937 Cologne,

Germany

e-mail: michael.hack1@uk-koeln.de; michaelhackl@live.de

M. Hackl, S. Lappen, K. J. Burkhart, T. Leschinger, M. Scaal, L. P. Müller, K. Wegmann

Cologne Center for Musculoskeletal Biomechanics, Medical

Faculty, University of Cologne, Cologne, Germany radial nerves change with variation of elbow positioning; and whether (2) flexion and joint insufflation increase the distance of the median and radial nerves to osseous landmarks after correcting for differences in size of the cadaveric specimens.

Methods The median and radial nerves were marked with a radiopaque thread in 11 fresh-frozen elbow specimens. Three-dimensional radiographic scans were performed in extension, in $90^{\circ}$ flexion, and after joint insufflations in neutral rotation, pronation, and supination. Trochlear and capitellar widths were analyzed. The distances of the median nerve to the medial and anterior edge of the trochlea and to the coronoid were measured. The distances of the radial nerve to the lateral and anterior edge of the capitulum and to the anterior edge of the radial head were measured. We analyzed the mediolateral nerve locations as a percentage function of the trochlear and capitellar widths to control for differences regarding the size of the specimens.

Results The mean distance of the radial nerve to the lateral edge of the capitulum as a percentage function of the capitellar width increased from $68 \% \pm 17 \%$ in extension to $91 \% \pm 23 \%$ in flexion (mean difference $=23 \%$; $95 \%$ confidence interval $[\mathrm{CI}], 5 \%-41 \% ; \mathrm{p}=0.01)$. With the numbers available, no such difference was observed

\section{K. J. Burkhart}

Clinic for Shoulder Surgery, Bad Neustadt/Saale, Germany

M. Hackl

Department of Anatomy I, University of Cologne, Cologne,

Germany

M. Scaal

Department of Anatomy II, University of Cologne, Cologne, Germany 
regarding the location of the median nerve in relation to the medial border of the trochlea (mean difference $=5 \%$; $95 \%$ $\mathrm{CI},-13 \%$ to $22 \%$; $\mathrm{p}=0.309)$. Flexion and joint insufflation increased the distance of the nerves to osseous landmarks. The mean distance of the median nerve to the coronoid tip was $5.4 \pm 1.3 \mathrm{~mm}$ in extension, $9.1 \pm 2.3 \mathrm{~mm}$ in flexion (mean difference $=3.7 \mathrm{~mm} ; 95 \% \mathrm{CI}, 2.04-5.36$ $\mathrm{mm} ; \mathrm{p}<0.001$ ), and $12.6 \pm 3.6 \mathrm{~mm}$ in flexion and insufflation (mean difference $=3.5 \mathrm{~mm} ; 95 \%$ CI, 0.81-6.19 $\mathrm{mm} ; \mathrm{p}=0.008$ ). The mean distance of the radial nerve to the anterior edge of the radial head increased from $4.7 \pm$ $1.8 \mathrm{~mm}$ in extension to $7.7 \pm 2.7 \mathrm{~mm}$ in flexion (mean difference $=3.0 \mathrm{~mm} ; 95 \% \mathrm{CI}, 0.96-5.04 \mathrm{~mm} ; \mathrm{p}=0.005$ ) and to $11.9 \pm 3.0 \mathrm{~mm}$ in flexion with additional joint insufflation (mean difference $=4.2 \mathrm{~mm} ; 95 \% \mathrm{CI}, 1.66-6.74$ $\mathrm{mm} ; \mathrm{p}=0.002)$.

Conclusions The radial nerve shifts medially during flexion from the lateral to the medial border of the inner third of the capitulum. The median nerve is located at the medial quarter of the joint. The distance of the median and radial nerves to osseous landmarks doubles from extension to $90^{\circ}$ flexion and triples after joint insufflation.

Clinical Relevance Elbow arthroscopy with anterior capsulectomy should be performed cautiously at the medial aspect of the joint to avoid median nerve lesions. Performing arthroscopic anterior capsulectomy in flexion at the lateral aspect of the joint and in slight extension at the medial edge of the capitulum could enhance safety of this procedure.

\section{Introduction}

The median and radial nerves lie in close relation to the ventral aspect of the elbow and are at risk of iatrogenic injury when performing arthroscopic arthrolysis with anterior capsulectomy for posttraumatic elbow stiffness. Contracture of the anterior joint capsule as a result of arthrofibrosis of the elbow reduces the capacity for joint distension during arthroscopy and thus leads to a decreased distance of the aforementioned nerves to osseous landmarks [8]. Consequently, nerve lesions represent a severe complication of arthroscopic anterior capsulectomy with a potentially devastating effect on the patient's clinical outcome $[9-13,15,18,22,23,25,28$, $29,32]$. They have been reported to occur in approximately $2.2 \%$ of patients undergoing arthroscopic arthrolysis [23].

Detailed knowledge of the anatomic course of the radial and median nerves can be of help for elbow surgeons to minimize risk of patient neurologic complications when performing arthroscopic anterior capsulectomy. The location of the median and radial nerves has been described in prior studies with a main focus on the relationship to arthroscopic portal placement [2, 6, 7, 21, 31, 33]. However, thus far, the bone-to-nerve distance has only been investigated by means of macroscopic measurements, which might predispose to inaccuracy $[19,21]$. As a result, there is a lack of reliable data regarding the influence of elbow flexion and joint insufflation on the distance of the median and radial nerves to osseous landmarks. Moreover, the influence of elbow positioning on nerve locations has not yet been investigated.

Hence, the purpose of this anatomic study was to precisely analyze the course of the median and radial nerves in relationship to osseous landmarks depending on elbow positioning and joint insufflation with an innovative investigational design. We hypothesized (1) that the locations of the median and radial nerves change with variation of elbow positioning; and (2) that flexion and joint insufflation increase the distance of the nerves to osseous landmarks after correcting for differences in size of the cadaveric specimens.

\section{Patients and Methods}

This study has been approved by the ethical committee of the Medical University of Cologne (approval number: 13-219). Eleven fresh-frozen cadaveric upper extremity specimens from 11 body donors of white origin were used for the present study. The mean age of donors at the time of death was 86 years (range, 74-95 years). The specimens came from five men and six women. Seven of the available elbow specimens were left extremities and four of them were right. The specimens were stored at $-20^{\circ} \mathrm{C}$ and thawed at room temperature immediately before dissection. Fluoroscopic and clinical examinations were performed to exclude specimens with restricted ROM as a result of osteoarthritis or previous surgery and trauma.

Specimens were dissected using a Henry approach. At first, the median nerve was identified medial to the distal biceps tendon. By means of gentle blunt dissection, we carefully followed the course of the nerve proximally along its course on the brachialis muscle and distally until its passage through the pronator muscle. The bicipital aponeurosis was left intact to avoid mobilization of the median nerve. Second, the radial nerve was located between the distal biceps tendon and the brachioradialis muscle. We carefully followed the course of the nerve from its passage through the lateral intermuscular septum and along its path-on the lateral aspect of the brachialis muscle-underneath the brachioradialis muscle until the deep branch enters its course between the deep and superficial head of the supinator muscle through Frohse's arcade. The nerves were prepared by careful blunt dissection to exclude 
the risk of mobilization from their original path. Dissection of the surrounding soft tissue was kept to a minimum to leave it intact. A fine, radiopaque thread was then placed and sutured onto each nerve at regular intervals of $2 \mathrm{~cm}$. Through prior testing, the minimal thickness of the thread necessary for sufficient visibility in a three-dimensional (3D) X-ray scan was defined to be $0.3 \mathrm{~mm}$. Great care was taken not to attach the thread to the surrounding soft tissue but only to the respective nerve and to avoid constriction of the nerve while performing the suture. Elbow flexion and extension as well as pronation and supination were then performed to verify that the nerve was not attached to the surrounding soft tissue by the suture and thereby diverted from its original path. The overlying subcutaneous and skin tissue was subsequently carefully readapted (Fig. 1). Specimen dissection was performed by a single surgeon $(\mathrm{KW})$.

Immediately after specimen dissection, 3-D x-ray imaging was performed using Arcadis Orbic (Siemens Healthcare Diagnostics GmbH, Eschborn, Germany) to visualize the radiopaque threads imitating the course of the respective nerve. Scans were performed in pronation, supination, and neutral forearm rotation with the elbow (1) in full extension; (2) in $90^{\circ}$ of flexion; and (3) in $90^{\circ}$ of flexion with additional joint insufflation with $20 \mathrm{cc}$ of $0.9 \%$ normal saline solution (Fig. 2). Through the digital radiologic evaluation software Impax EE (Agfa Healthcare $\mathrm{GmbH}$, Bonn, Germany), 3-D reconstructions of the obtained imaging data were built.

An axial view through the motion axis of the distal humerus was then extracted. The capitellar and trochlear widths as well as the distances of the median nerve to the medial edge of the trochlea and to the anterior edge of the trochlea were measured. Moreover, the distances of the radial nerve to the lateral and to the anterior edge of the capitulum were evaluated (Fig. 3A). A sagittal view through the coronoid tip was then extracted by aligning the

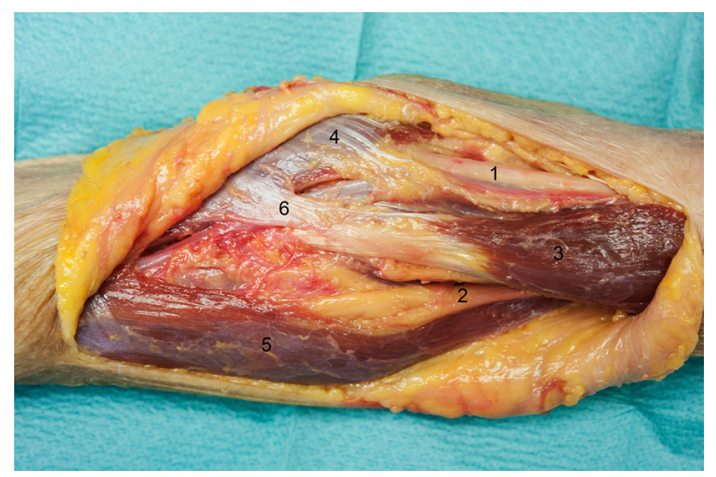

Fig. 1 Illustration shows the performed specimen dissection. $1=$ median nerve; $2=$ radial nerve; $3=$ biceps muscle; $4=$ pronator teres muscle; 5 = brachioradialis muscle; $6=$ bicipital aponeurosis. planes along the longitudinal axis of the ulna. Thereby, the closest distance of the median nerve to the anterior edge of the coronoid tip could be measured (Fig. 3B). Similarly, a sagittal view through the center of the radial head was extracted and the closest distance of the radial nerve to the anterior border of the radial head was evaluated (Fig. 3C). Measurements of the extracted images were performed using the software Image-Pro Plus 6.0 (Media Cybernetics Inc, Rockville, MD, USA).

Mean, minimum, maximum, and SD were calculated in millimeters for each measured value. We evaluated the mediolateral nerve locations as a percentage function of the trochlear and capitellar widths to control for differences regarding the size of the specimens. Normal distribution of data was confirmed by using the Kolmogorov-Smirnov procedure. A one-sided analysis of variance with a post hoc Scheffé test was performed to evaluate significant differences of measured values regarding elbow positioning and joint insufflation. The level of significance was set to 0.05 . Pearson correlation coefficient (r) with a $95 \%$ confidence interval (CI) was used to assess correlation of obtained data. Three blinded observers extracted the images and performed the measurements. Interobserver agreement was validated by the intraclass correlation coefficient (ICC).

\section{Results}

Forearm rotation did not influence the location of the median or radial nerves at the level of the distal humerus or at the level of the coronoid tip and the radial head, respectively. Flexion of the elbow led to a medial shift of

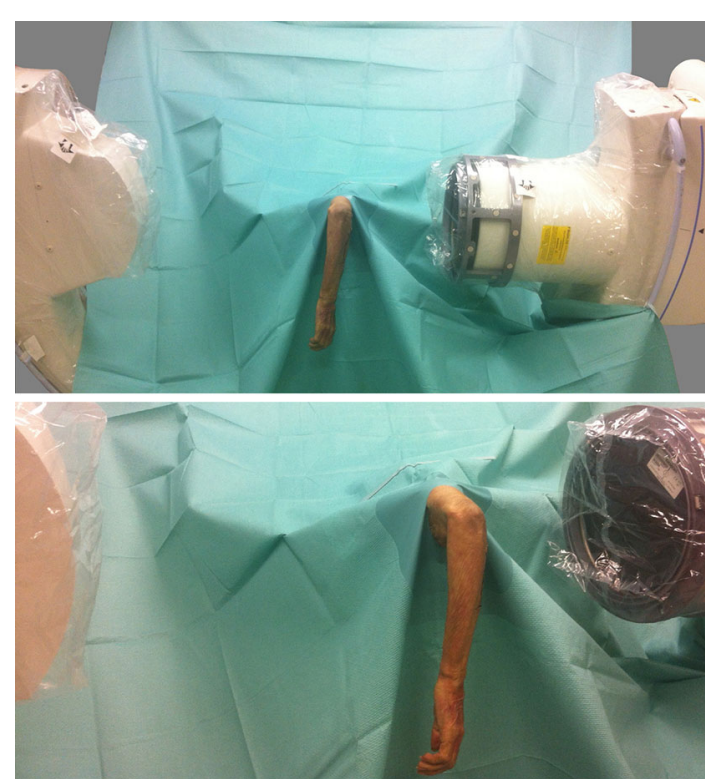

Fig. 2 Setup shown for obtaining imaging studies in $90^{\circ}$ of flexion. 

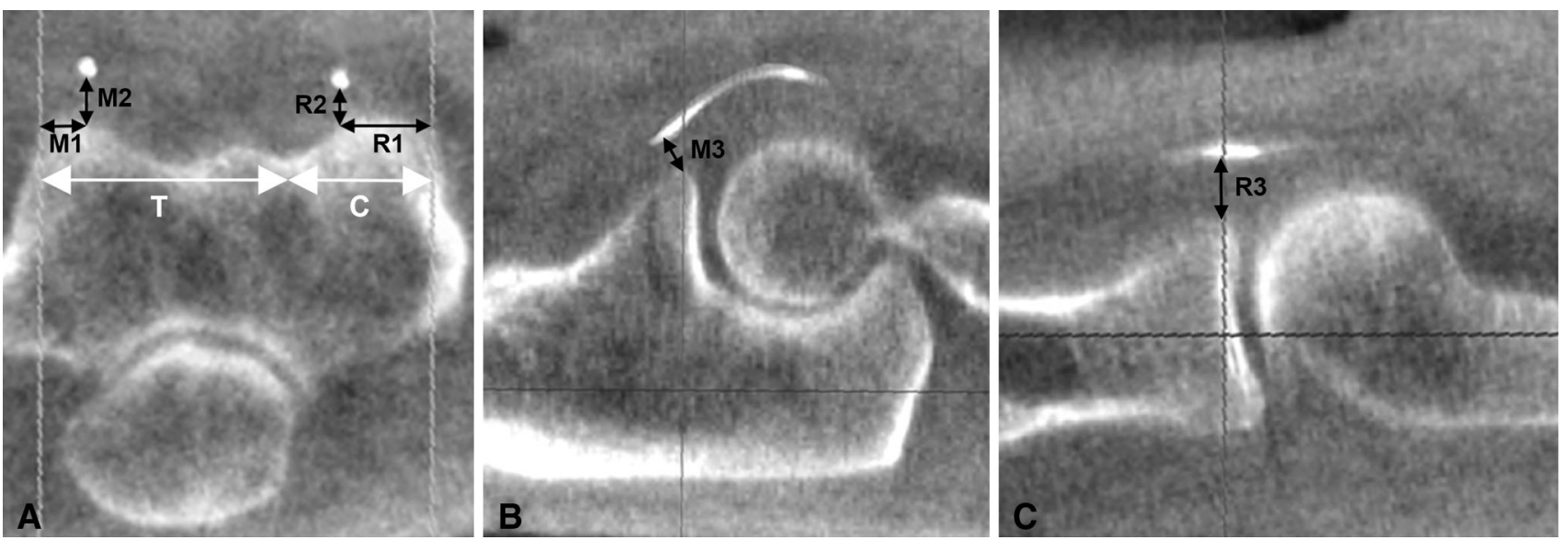

Fig. 3A-C Illustration shows the performed measurements. (A) Axial view shows measurements of trochlear width $(\mathrm{T})$, capitellar width $(\mathrm{C})$, distance of the median nerve to the medial and anterior borders of the trochlea (M1/M2), and distance of the radial nerve to the lateral and anterior edges of the capitulum (R1/R2). (B) Sagittal view is shown

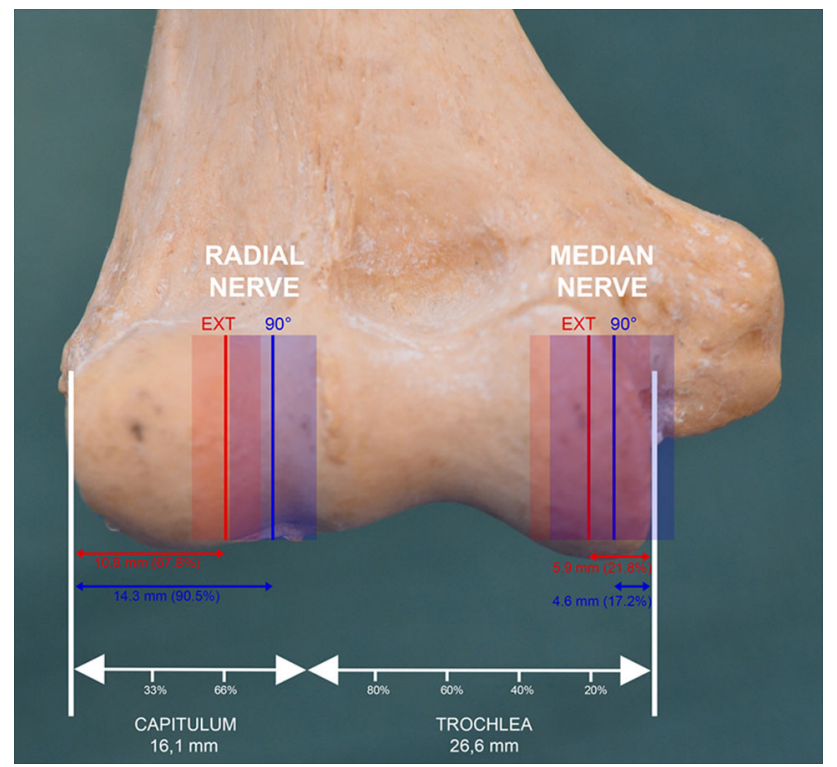

Fig. 4 Median and radial nerve locations in the coronal plane are shown. Mean values for capitellar and trochlear width are shown. Mean values \pm SD for radial nerve distance to the lateral edge of the capitulum and median nerve distance to the medial edge of the trochlea are shown. EXT $=$ full extension; $90^{\circ}=90^{\circ}$ of flexion.

the radial nerve. The mean distance of the radial nerve to the lateral border of the capitulum-expressed as a percentage function of the capitellar width-was $68 \% \pm 17 \%$ in extension and increased to $91 \% \pm 23 \%$ in flexion (mean difference $=23 \% ; 95 \% \mathrm{CI}, 5 \%-41 \% ; \mathrm{p}=0.01)$. With the numbers available, no such difference was observed regarding the location of the median nerve. The mean distance of the median nerve to the medial edge of the trochlea as a percentage function of the trochlear width was through the coronoid tip: measurement of the closest distance of the median nerve to the coronoid tip (M3). (C) Sagittal view through the center of the radial head is shown: measurement of the closest distance of the radial nerve to the radial head.

$22 \% \pm 19 \%$ in extension and $17 \% \pm 22 \%$ in flexion (mean difference: $5 \%$; 95\% CI, $-13 \%$ to $22 \%$; $\mathrm{p}=0.309$ ) (Fig. 4 ; Table 1).

Flexion and joint insufflation increased the distance of the median and radial nerves to osseous landmarks. The distance of the median nerve to the anterior border of the trochlea was $4.8 \pm 1.5 \mathrm{~mm}$ in extension, $8.4 \pm 2.4 \mathrm{~mm}$ in flexion (mean difference $=3.6 \mathrm{~mm} ; 95 \% \mathrm{CI}, 1.82-5.38$ $\mathrm{mm} ; \mathrm{p}<0.001$ ), and $13.4 \pm 3.6 \mathrm{~mm}$ in flexion and joint insufflation (mean difference $=5.0 \mathrm{~mm}$; 95\% CI, 2.28-7.72 $\mathrm{mm} ; \mathrm{p}<0.001$ ). Regarding the anterior tip of the coronoid process, the bone-to-median nerve distance was $5.4 \pm 1.3$ $\mathrm{mm}$ in extension, $9.1 \pm 2.3 \mathrm{~mm}$ in $90^{\circ}$ of elbow flexion (mean difference $=3.7 \mathrm{~mm}$; 95\% CI, 2.04-5.36 mm; $\mathrm{p}<$ 0.001 ), and $12.6 \pm 3.6 \mathrm{~mm}$ in flexion with additional joint insufflation (mean difference $=3.5 \mathrm{~mm} ; 95 \% \mathrm{CI}, 0.81-6.19$ $\mathrm{mm} ; \mathrm{p}=0.008$ ) (Fig. 5; Table 1). The distance of the radial nerve to the anterior edge of the capitulum was $5.5 \pm 1.8$ $\mathrm{mm}$ in extension and $10.8 \pm 3.2 \mathrm{~mm}$ in flexion (mean difference $=5.3 \mathrm{~mm} ; 95 \% \mathrm{CI}, 2.99-7.61 \mathrm{~mm} ; \mathrm{p}<0.001$ ). Additional joint insufflation increased the distance to 17.0 $\pm 3.1 \mathrm{~mm}$ (mean difference $=6.2 \mathrm{~mm} ; 95 \%$ CI, 3.40-9.00 $\mathrm{mm} ; \mathrm{p}<0.001)$. The mean distance of the radial nerve to the anterior edge of the radial head was $4.7 \pm 1.8 \mathrm{~mm}$ in full extension and increased to $7.7 \pm 2.7 \mathrm{~mm}$ in $90^{\circ}$ of elbow flexion (mean difference $=3.0 \mathrm{~mm} ; 95 \% \mathrm{CI}$, $0.96-5.04 \mathrm{~mm} ; \mathrm{p}=0.005$ ) and to $11.9 \pm 3.0 \mathrm{~mm}$ in flexion with additional joint insufflation (mean difference $=4.2$ $\mathrm{mm}$; 95\% CI, 1.66-6.74 mm; $\mathrm{p}=0.002$ ) (Fig. 6; Table 1). The anterior distance of the nerves to osseous landmarks correlated with the width of the articular surface $(\mathrm{r}=0.62$; 95\% CI, 0.49-0.83; $\mathrm{p}=0.021)$. ICCs for the measured values averaged 0.95 and ranged from 0.93 to 0.99 . 
Table 1. Distance of the median and radial nerves to osseous landmarks in relation to elbow positioning and joint insufflation*

\begin{tabular}{|c|c|c|c|c|c|}
\hline & Mean & SD & Minimum & Maximum & $\mathrm{p}$ value \\
\hline \multicolumn{6}{|l|}{ Distance of the median nerve } \\
\hline \multicolumn{6}{|c|}{ To the medial border of the trochlea $(\mathrm{M} 1 ; \mathrm{mm})^{\dagger}$} \\
\hline Full extension & 5.9 & \pm 4.0 & -2.3 & 10.4 & \multirow{3}{*}{0.309} \\
\hline $90^{\circ}$ of flexion & 4.6 & \pm 3.7 & -2.8 & 10.8 & \\
\hline $90^{\circ}$ of flexion $+20 \mathrm{cc}$ insufflation & 3.4 & \pm 6.3 & -5.0 & 10.3 & \\
\hline \multicolumn{6}{|c|}{ To the anterior edge of the trochlea (M2; mm) } \\
\hline Full extension & 4.8 & \pm 1.5 & 3.0 & 7.7 & \\
\hline $90^{\circ}$ of flexion & 8.4 & \pm 2.4 & 4.2 & 11.5 & $<0.001^{*}$ \\
\hline $90^{\circ}$ of flexion $+20 \mathrm{cc}$ insufflation & 13.4 & \pm 3.6 & 6.6 & 17.3 & $<0.001^{*}$ \\
\hline \multicolumn{6}{|l|}{ To the coronoid tip (M3; mm) } \\
\hline Full extension & 5.4 & \pm 1.3 & 3.1 & 7.3 & \\
\hline $90^{\circ}$ of flexion & 9.1 & \pm 2.3 & 5.9 & 13.8 & $<0.001^{*}$ \\
\hline $90^{\circ}$ of flexion $+20 \mathrm{cc}$ insufflation & 12.6 & \pm 3.6 & 8.6 & 19.3 & $0.008^{*}$ \\
\hline \multicolumn{6}{|l|}{ Distance of the radial nerve } \\
\hline \multicolumn{6}{|c|}{ To the lateral border of the capitulum $(\mathrm{R} 1 ; \mathrm{mm})$} \\
\hline Full extension & 10.8 & \pm 2.5 & 7.6 & 15.2 & \multirow{3}{*}{$0.010^{\sharp}$} \\
\hline $90^{\circ}$ of flexion & 14.4 & \pm 3.7 & 9.0 & 20.8 & \\
\hline $90^{\circ}$ of flexion $+20 \mathrm{cc}$ insufflation & 15.1 & \pm 4.0 & 9.1 & 22.8 & \\
\hline \multicolumn{6}{|c|}{ To the anterior edge of the capitulum $(\mathrm{R} 2 ; \mathrm{mm})$} \\
\hline Full extension & 5.5 & \pm 1.8 & 3.6 & 8.6 & \\
\hline $90^{\circ}$ of flexion & 10.8 & \pm 3.2 & 5.3 & 16.0 & $<0.001^{*}$ \\
\hline $90^{\circ}$ of flexion $+20 \mathrm{cc}$ insufflation & 17.0 & \pm 3.1 & 13.2 & 21.3 & $<0.001^{*}$ \\
\hline \multicolumn{6}{|c|}{ To the anterior edge of the radial head $(\mathrm{R} 3 ; \mathrm{mm})$} \\
\hline Full extension & 4.7 & \pm 1.8 & 2.8 & 7.9 & \\
\hline $90^{\circ}$ of flexion & 7.7 & \pm 2.7 & 5.2 & 13.2 & $0.005^{*}$ \\
\hline $90^{\circ}$ of flexion $+20 \mathrm{cc}$ insufflation & 11.9 & \pm 3.0 & 8.9 & 18.3 & $0.002^{*}$ \\
\hline
\end{tabular}

* Twenty cubic centimeters of normal saline solution; ${ }^{\dagger}$ negative values for M1 represent a median nerve location medial to the trochlea; significant difference $(\mathrm{p}<0.05)$.

\section{Discussion}

Arthroscopic arthrolysis represents a commonly used tool for treatment of elbow stiffness [11-15, 23] that can effectively increase the patients' ROM. Nevertheless, nerve injuries have been reported in $2.2 \%$ of cases as a result of the close proximity of major nerves to the joint [23], which is why many anatomic studies focused on the location of these nerves-mostly with regard to arthroscopic portal placement $[2,6,7,21,31,33]$. The median and radial nerves are in particular jeopardy during anterior capsulectomy, yet their location in relation to osseous landmarks has been described only through macroscopic measurements prone to inaccuracy $[17,19,21]$. Thus far, precise information on the influence of joint flexion and insufflation to increase the bone-to-nerve distance at the anterior aspect of the elbow is lacking. Moreover, none of the previous studies evaluated the influence of elbow positioning on the mediolateral location of the median and radial nerves. Therefore, the purpose of the present study was to analyze the anatomic course of the median and radial nerves in relation to bony landmarks depending on elbow positioning and joint distension by means of an innovative investigational design. We hypothesized (1) that the locations of the median and radial nerves change with variation of elbow positioning; and (2) that flexion as well as joint insufflation increase the distance of the median and radial nerves to osseous landmarks after correcting for differences in size of the cadaveric specimens.

Limitations of the study are those common to cadaveric studies. A limited sample size of 11 specimens was available from only white donors; therefore, a population, age, or sex bias cannot be excluded. The cadaveric study design does not fully reproduce physiologic in vivo conditions and could subsequently bias the results. The joint capsule of the specimens might be less flexible when compared with in vivo conditions. To avoid bursting of the joint capsule, insufflation was kept to $20 \mathrm{cc}$ of normal saline solution in every specimen to obtain comparable results. In patients with arthrofibrosis of the elbow, the 
Fig. 5A-D Illustration shows the distance of the median nerve to the coronoid tip on sagittal view: (A) extension; (B) $90^{\circ}$ of flexion; (C) $90^{\circ}$ of flexion + joint insufflation $(20 \mathrm{cc} 0.9 \%$ normal saline solution); (D) mean values in relation to elbow positioning.
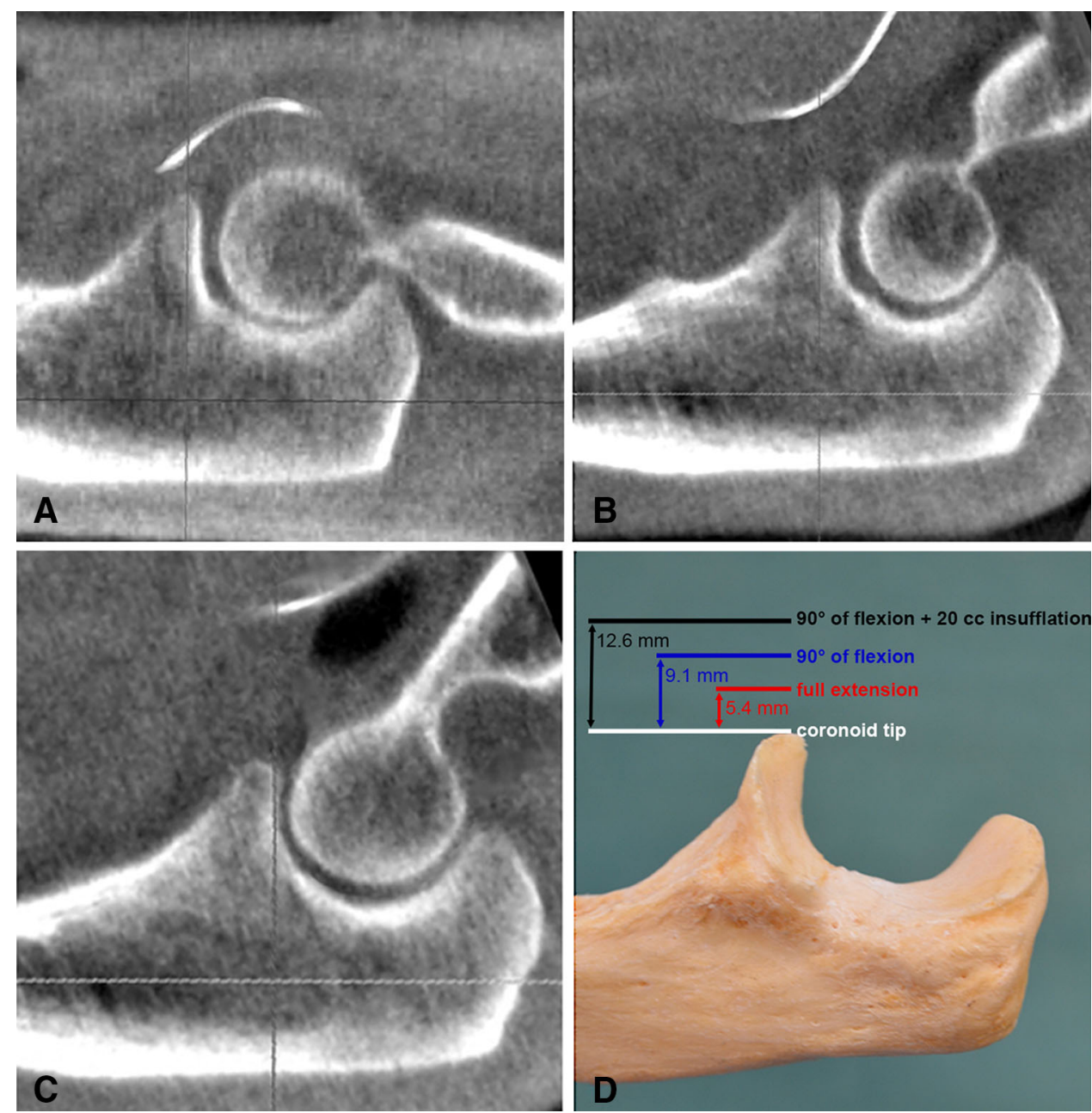

capacity for joint distension is diminished, increasing the potential risk of neurologic complications during arthroscopic anterior capsulectomy $[1,3-5,8-16,18,20,23-30$, $32,34]$. Haapaniemi et al. [9] reported a case of simultaneous median and radial nerve transection during arthroscopic anterior capsulectomy, which they attributed mainly to poor visualization as a result of insufficient joint distension resulting from stiffness and adhesions of the joint capsule. Specimens in our study did not have arthrofibrosis, which might limit the applicability of our data in this patient group. Moreover, our study did not evaluate the capsule-to-nerve distance, which has been analyzed in previous studies [17, 19]. Although meticulously performed and kept to a minimum, specimen dissection could also bias the obtained results. Investigation by means of MRI could not be performed because arm positioning as maintained in elbow arthroscopy was not feasible in an MRI.

The median nerve usually is located anterior to the medial quarter of the trochlea but can also appear medial to the trochlea, which has to be remembered when performing anterior capsulectomy of the medial portion of the joint capsule. Previous studies have reported that the median and radial nerves lie in close relation to the anteromedial and anterolateral portals [2, 6, 7, 31, 33]. Stothers et al. [31] described the portal-to-nerve distance for the medial nerve and the anteromedial portal is only $2.1 \mathrm{~mm}$ in extension and increases to $7.0 \mathrm{~mm}$ in $90^{\circ}$ of elbow flexion. The median nerve was found medial to the trochlea in one-third of all cases in our study; therefore, we can confirm that the median nerve is closely related to the anteromedial portal. Omid et al. [21] reported that the radial nerve is always located medial to the capitulum, but we were unable to confirm these findings in our study. In the present study, the radial nerve was found to shift medially during elbow flexion. In extension, the radial nerve is located in front of the capitulum between its middle and inner third. In $90^{\circ}$ of flexion, the nerve courses in front of the medial border of the capitulum. This information can be of use when performing arthroscopic arthrolysis. During anterior capsulectomy in front of the lateral portion of the trochlea, the elbow can be slightly extended to cause a lateral shift of the radial nerve, thereby decreasing the risk of nerve transection. Similarly, when the lateral aspect of the joint capsule 
Fig. 6A-D Illustration shows radial nerve distance to the radial head on sagittal view: (A) extension; (B) $90^{\circ}$ of flexion; (C) $90^{\circ}$ of flexion + joint insufflation $(20$ cc $0.9 \%$ normal saline solution); (D) mean values in relation to elbow positioning.
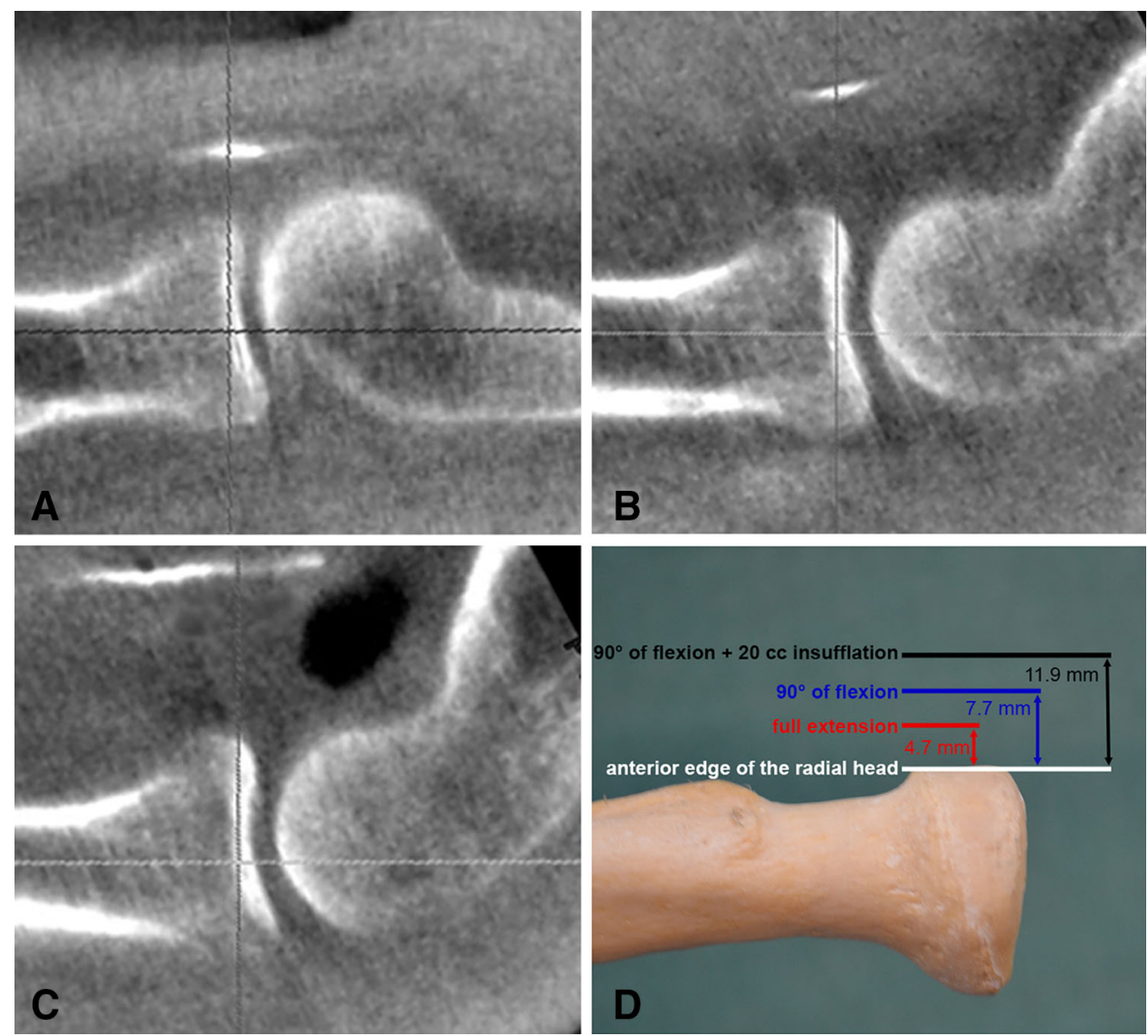

is being addressed, elbow flexion can diminish the chance of neurologic complications. Although forearm rotation did not influence the results in our study, Unlu et al. [33] were able show that pronation increases the distance of the radial nerve to the anterolateral portal. On the other hand, Drescher et al. [6] found that the distance of the median nerve to the anteromedial portal can be improved by supination of the forearm.

Joint flexion and distension can help to increase the bone-to-nerve distance at the anterior aspect of the elbow. Therefore, the risk of neurological complications during arthroscopic arthrolysis of the elbow may be reduced. Previous studies have investigated the influence of elbow flexion and joint distension only by means of gross anatomic dissection [17, 19]. Therefore, comparable results before and after insufflation could only be obtained by use of matched pairs [19]. Our study design allowed for an identical testing sequence (extension; flexion; flexion and joint insufflation) in every specimen. The in vivo positioning of the elbow during arthroscopy could be closely reproduced as a result of the testing setup. The results of our study show that $90^{\circ}$ of elbow flexion doubles the boneto-nerve distance when compared with full extension. Additional joint insufflation with $20 \mathrm{cc}$ of normal saline solution approximately triples the distance of the median and radial nerves to osseous landmarks. Although joint insufflation increases the bone-to-nerve distance, Miller et al. were able to show that capsule-to-nerve distance does not improve with joint distension but rather remains unchanged [19]. This has to be carefully considered when performing arthroscopic anterior capsulectomy.

The results of our study show that the anterior distances of the median and radial nerves to the trochlea and the capitulum as well as to the coronoid tip and the radial head double from full extension to $90^{\circ}$ of elbow flexion and triple after additional joint insufflation. This illustrates the increased risk of neurologic complications during arthroscopic elbow arthrolysis in patients with arthrofibrosis where joint insufflation might be limited as a result of scarring of the anterior capsule. On the coronal plane, the median nerve is located at the medial quarter of the trochlea but can also be found medial to the trochlea in select cases. This has to be carefully considered when performing anterior capsulectomy of the medial portion of the joint capsule. The radial nerve shifts medially during elbow flexion and can be found in front of the medial border of the capitulum in $90^{\circ}$ of flexion. Slight extension of the elbow can be helpful to avoid radial nerve lesions when addressing the joint capsule in front of the lateral edge of the trochlea. Vice versa, increased flexion may be used 
during anterior capsulectomy of the lateral portion of the joint capsule.

\section{References}

1. Achtnich A, Forkel P, Metzlaff S, Petersen W. [Arthroscopic arthrolysis of the elbow joint] [in German]. Oper Orthop Traumatol. 2013;25:205-214.

2. Adolfsson L. Arthroscopy of the elbow joint: a cadaveric study of portal placement. J Shoulder Elbow Surg. 1994;3:53-61.

3. Andrews JR, Carson WG. Arthroscopy of the elbow. Arthroscopy. 1985;1:97-107.

4. Ball CM, Meunier M, Galatz LM, Calfee R, Yamaguchi K. Arthroscopic treatment of post-traumatic elbow contracture. J Shoulder Elbow Surg. 2002;11:624-629.

5. Cefo I, Eygendaal D. Arthroscopic arthrolysis for posttraumatic elbow stiffness. J Shoulder Elbow Surg. 2011;20:434-439.

6. Drescher H, Schwering L, Jerosch J, Herzig M. [The risk of neurovascular damage in elbow joint arthroscopy. Which approach is better: anteromedial or anterolateral?] [in German]. Z Orthop Ihre Grenzgeb. 1994;132:120-125.

7. Field LD, Altchek DW, Warren RF, O'Brien SJ, Skyhar MJ, Wickiewicz TL. Arthroscopic anatomy of the lateral elbow: a comparison of three portals. Arthroscopy. 1994;10:602-607.

8. Gallay SH, Richards RR, O'Driscoll SW. Intraarticular capacity and compliance of stiff and normal elbows. Arthroscopy. 1993;9:9-13.

9. Haapaniemi T, Berggren M, Adolfsson L. Complete transection of the median and radial nerves during arthroscopic release of post-traumatic elbow contracture. Arthroscopy. 1999;15:784787.

10. Kelly EW, Morrey BF, O'Driscoll SW. Complications of elbow arthroscopy. J Bone Joint Surg Am. 2001;83:25-34.

11. Kim SJ, Moon HK, Chun YM, Chang JH. Arthroscopic treatment for limitation of motion of the elbow: the learning curve. Knee Surg Sports Traumatol Arthrosc. 2011;19:1013-1018.

12. Kim SJ, Shin SJ. Arthroscopic treatment for limitation of motion of the elbow. Clin Orthop Relat Res. 2000;375:140-148.

13. Kodde IF, van Rijn J, van den Bekerom MP, Eygendaal D. Surgical treatment of post-traumatic elbow stiffness: a systematic review. J Shoulder Elbow Surg. 2013;22:574-580.

14. Lapner PC, Leith JM, Regan WD. Arthroscopic débridement of the elbow for arthrofibrosis resulting from nondisplaced fracture of the radial head. Arthroscopy. 2005;21:1492.

15. Lichtenberg S. [Elbow contracture. Use of an arthroscopic procedure or an an open procedure?] [in German]. Obere Extremität. 2014;9:163-171.

16. Lindenhovius AL, Jupiter JB. The posttraumatic stiff elbow: a review of the literature. J Hand Surg Am. 2007;32:16051623.
17. Lynch GJ, Meyers JF, Whipple TL, Caspari RB. Neurovascular anatomy and elbow arthroscopy: inherent risks. Arthroscopy. 1986;2:190-197.

18. Marti D, Spross C, Jost B. The first 100 elbow arthroscopies of one surgeon: analysis of complications. J Shoulder Elbow Surg. 2013;22:567-573.

19. Miller CD, Jobe CM, Wright MH. Neuroanatomy in elbow arthroscopy. J Shoulder Elbow Surg. 1995;4:168-174.

20. Nguyen D, Proper SI, MacDermid JC, King GJ, Faber KJ. Functional outcomes of arthroscopic capsular release of the elbow. Arthroscopy. 2006;22:842-849.

21. Omid R, Hamid N, Keener JD, Galatz LM, Yamaguchi K. Relation of the radial nerve to the anterior capsule of the elbow: anatomy with correlation to arthroscopy. Arthroscopy. 2012;28: 1800-1804.

22. Park JY, Cho CH, Choi JH, Lee ST, Kang CH. Radial nerve palsy after arthroscopic anterior capsular release for degenerative elbow contracture. Arthroscopy. 2007;23:1360.e1-3.

23. Pederzini LA, Nicoletta F, Tosi M, Prandini M, Tripoli E, Cossio A. Elbow arthroscopy in stiff elbow. Knee Surg Sports Traumatol Arthrosc. 2013;22:467-473.

24. Phillips BB, Strasburger S. Arthroscopic treatment of arthrofibrosis of the elbow joint. Arthroscopy. 1998;14:38-44.

25. Ruch DS, Poehling GG. Anterior interosseus nerve injury following elbow arthroscopy. Arthroscopy. 1997;13:756-758.

26. Salini V, Palmieri D, Colucci C, Croce G, Castellani ML, Orso CA. Arthroscopic treatment of post-traumatic elbow stiffness. J Sports Med Phys Fitness. 2006;46:99-103.

27. Savoie FH 3rd, Nunley PD, Field LD. Arthroscopic management of the arthritic elbow: indications, technique, and results. J Shoulder Elbow Surg. 1999;8:214-219.

28. Schmidt T, Stangl R. [Indications, complications and results of elbow arthroscopy] [in German]. Obere Extremität. 2013;8:220-225.

29. Small NC. Complications in arthroscopic surgery performed by experienced arthroscopists. Arthroscopy. 1988;4:215-221.

30. Somanchi BV, Funk L. Evaluation of functional outcome and patient satisfaction after arthroscopic elbow arthrolysis. Acta Orthop Belg. 2008;74:17-23.

31. Stothers K, Day B, Regan WR. Arthroscopy of the elbow: anatomy, portal sites, and a description of the proximal lateral portal. Arthroscopy. 1995;11:449-457.

32. Thomas MA, Fast A, Shapiro D. Radial nerve damage as a complication of elbow arthroscopy. Clin Orthop Relat Res. 1987;215:130-131.

33. Unlu MC, Kesmezacar H, Akgun I, Ogut T, Uzun I. Anatomic relationship between elbow arthroscopy portals and neurovascular structures in different elbow and forearm positions. J Shoulder Elbow Surg. 2006;15:457-462.

34. Wu X, Wang H, Meng C, Yang S, Duan D, Xu W, Liu X, Tang M, Zhao J. Outcomes of arthroscopic arthrolysis for the posttraumatic elbow stiffness. Knee Surg Sports Traumatol Arthrosc. 2014 May 15 [Epub ahead of print]. 